\title{
A HOSPITALIDADE NO (ECO)TURISMO DA ENSEADA DE ABRÃ̃O - ILHA GRANDE (RJ): REFLEXOS SOBRE O MEIO \\ AMBIENTE LOCAL
}

\author{
THE HOSPITALITY IN (ECO)TOURISM OF THE ABRAÃO BAY \\ - ILHA GRANDE (RJ): REFLECTIONS ON THE LOCAL \\ ENVIRONMENT
}

\begin{abstract}
Nadja Maria Castilho Costa Professora Adjunta do Instituto de Geografia da Universidade do Estado do Rio de Janeiro - UERJ, líder do Grupo de Estudos Ambientais / UERJ e pesquisadora do CNPq . E-mail: nadjacastilho@gmail.com
\end{abstract}

Luiz Renato dos Santos Alves Aluno de graduação do Instituto de Geografia da Universidade do Estado do Rio de Janeiro - UERJ, bolsista de Iniciação Científica - PIBIC/CNPq. E-mail: alves_r@yahoo.com.br

\begin{abstract}
RESUMO
Nos últimos quinze anos, tem-se observado na Ilha Grande, litoral sul do Estado do Rio de Janeiro, um intenso processo de turistificação, estimulado pelo seu exuberante e diversificado quadro natural. Este fenômeno despertou inúmeras preocupações devido: a fragilidade dos ecossistemas locais, a especulação imobiliária, o crescimento demográfico e a criação de uma infraestrutura turística sem planejamento. O objetivo do presente trabalho é avaliar como a rede hoteleira da Enseada de Abraão, local de maior concentração de equipamentos e infraestrutura turística, vem atuando e os reflexos ambientais (positivos e/ou negativos) decorrentes da atividade, visando contribuir ao desenvolvimento sustentável do ecoturismo. Metodologicamente, as análises foram realizadas sob a ótica quantitativa e qualitativa através da aplicação de questionários aos proprietários/gerentes dos hotéis e análises de campo. Como resultado principal foi observado que a rede hoteleira não vem contribuindo ao desenvolvimento sustentável da atividade ecoturística, se constituindo em agentes catalisadores de impactos ambientais. Mais de $70 \%$ dos estabelecimentos não oferecem qualquer tipo de atividade de valorização ambiental e cultural, bem como, há a ausência de condições adequadas de infraestrutura sanitária (deposição de efluentes e resíduos sólidos na drenagem que chega às praias). Mais de $50 \%$ dos empregados e pouco mais de $75 \%$ dos produtos consumidos pelos turistas através da rede hoteleira, não são locais.
\end{abstract}

Palavras-Chave: ecoturismo, rede hoteleira, território, impacto ambiental e Ilha Grande.

Geo UERJ - Ano 14, nº. 23, v. 2, 2º semestre de 2012 p. 389-412

ISSN: 1415-7543 E-ISSN: 1981-9021

http://www.e-publicacoes.uerj.br/index.php/geouerj 


\begin{abstract}
Ilha Grande, an isle located in south coast of Rio de Janeiro State, suffered intensification of tourism process stimulated by its exuberant and diverse natural picture. This phenomenon developed several worries due to: the fragility of local ecosystems, ground and property speculation, demographic growth and generation of non planned tourism infrastructure. The objective of the present work is the evaluation of hotel network in Abraão Bay, where one find the most concentration of tourism infrastructure and equipment, and the environmental reflex (positive and/or negative) due to such activities, in order to contribute to a sustainable ecotourism development. The methodological analysis where done under the quantitative and qualitative optics through the questionnaires application for hotel managers and field analysis. As a main result it was observed that hotel network has not contributed to sustainable development of tourism activity but otherwise as environmental impacts catalytic agent. More than $70 \%$ of the enterprises does not offer any type of activity to improve environment and cultural value, and shows complete inadequate sanitary infrastructure conditions (like overthrow of effluents and solid residues in drainage that reaches the beach). More than $50 \%$ of the employees and exceeding $75 \%$ of products consumed by the tourists in such hotel network are not composed by locals.
\end{abstract}

Key-words: ecotourism, hotel network, territory, environmental impact, Ilha Grande.

Geo UERJ - Ano 14, nº 23 , v. 2, $2^{\circ}$ semestre de 2012 p. 389-412

ISSN: 1415-7543 E-ISSN: 1981-9021

http://www.e-publicacoes.uerj.br/index.php/geouerj 


\section{INTRODUÇÃO}

O turismo é uma das atividades econômicas mais importantes no quadro mundial. Auxiliado pelas geotecnologias e pela lógica da globalização, esta atividade propaga-se absorvendo culturas, economias, grupos, instituições e, por consequiência, construindo e reconstruindo territórios.

No caso específico do território fluminense, segundo RIBEIRO (2003), três atributos geográficos são considerados fontes de atração e/ou reconstrução do espaço visando o desenvolvimento do turismo: o quadro natural, as vias de acesso e o elemento histórico associado às atividades econômicas. Em consonância com uma dessas premissas, a Ilha Grande localizada no litoral sul do Estado do Rio de Janeiro, possui como principal atrativo, seu exuberante quadro natural, formado por vegetação de Mata Atlântica, que congrega: fauna diversificada, enseadas, rios, cachoeiras, mangues, planícies, montanhas e picos.

O declínio de determinadas atividades em seu território foi de suma importância para a consolidação do processo de turistificação. A desativação do Instituto Prisional Candido Mendes, durante a década de 1990, foi a principal transformação territorial. Paralelamente, ocorreu a desarticulação da atividade pesqueira, onde seus fixos passaram por um processo de (re)territorialização para atender a indústria da hospitalidade, principalmente na Vila do Abraão, local de maior incidência de fábricas de sardinha, até aquela época (COSTA, 2010). A partir de então, a população local passou a se inserir na nova dinâmica, para atender as demandas de mão-de-obra.Neste contexto, a Vila do Abraão localizada na face continental da Ilha Grande, passa a sofrer intenso processo de urbanização engendrado pelo turismo, demandando e desenvolvendo uma infra-estrutura de equipamentos urbanos, com destaque para a rede hoteleira. Este fenômeno, associado à especulação imobiliária e ao crescimento demográfico despertou inúmeras preocupações, devido à fragilidade dos ecossistemas locais.

Assim sendo, o objetivo do presente trabalho é avaliar a intervenção da rede hoteleira no espaço da Enseada de Abraão, local de maior concentração de equipamentos e infra-estrutura turística na Ilha Grande, analisando os impactos (positivos e/ou negativos) decorrentes de suas atividades visando contribuir ao

Geo UERJ - Ano 14, nº 23, v. 2, 2º semestre de 2012 p. 389-412

ISSN: 1415-7543 E-ISSN: 1981-9021

http://www.e-publicacoes.uerj.br/index.php/geouerj 
desenvolvimento do turismo na natureza, particularmente do ecoturismo, em bases sustentáveis.

Esta investigação justifica-se pela importância da indústria da hospitalidade como sendo um dos principais agentes transformadores de um território, podendo assim, contribuir à minimização dos impactos negativos e à maximização dos positivos, a partir do planejamento e gestão territorial adequados dos meios físico, biótico e social da ilha.

\section{ÁREA DE ESTUDO: UM OLHAR GEOGRÁFICO SOBRE A ILHA GRANDE}

A Ilha Grande é um distrito do município de Angra dos Reis que, juntamente com Itaguaí, Mangaratiba, Paraty e Rio Claro, compõem a Região Turística da Costa Verde localizada no litoral sul fluminense. Em sua face oceânica, na vertente sul, localizam-se as Vilas de Proveta e Dois Rios, sendo esta última, o local da extinta Colônia Prisional Candido Mendes. Na face voltada para o continente, vertente norte, localiza-se as Vilas de Araçatiba e Abraão tendo, esta, o maior aglomerado urbano e infra-estrutura turística de toda a ilha, se constituindo no recorte espacial da presente investigação.

No que tange ao quadro natural, a ilha é um maciço residual da Serra do Mar, apresentando encostas de alta declividade, contendo escarpas, costões e pontões rochosos, sendo seus maiores expoentes os picos da Pedra D’Água com 1.011 metros e o do Papagaio com 989 metros (GAMA et al, 2009). O seu entorno é composto por estreitas planícies fluviais e flúvio-marinhas para onde converge a drenagem que vem das encostas. Sua área é de $193 \mathrm{Km}^{2}$ conferindo-lhe o posto de maior ilha do Estado do Rio de Janeiro. Seu perímetro de $157 \mathrm{~km}$ é extremamente acidentado, apresentando 15 enseadas, 39 praias, 41pontas, 3 pequenos estuários, 2 lagoas e diversos mangues em pelos menos 6 pontos diferentes (CREED, 2009, p.249). O somatório destes atributos reserva à Ilha Grande feições paisagísticas únicas e de primal interesse ao desenvolvimento do turismo.

O processo de ocupação e uso do solo na ilha Grande é anterior à colonização brasileira. Os habitantes que, inicialmente, ocupavam a região exercendo atividades como a coleta, a caça e a pesca, deixaram suas marcas no espaço como, por exemplo, as

Geo UERJ - Ano 14, nº 23, v. 2, $2^{\circ}$ semestre de 2012 p. 389-412

ISSN: 1415-7543 E-ISSN: 1981-9021

http://www.e-publicacoes.uerj.br/index.php/geouerj 
trilhas utilizadas mais tarde pelos portugueses, no processo de colonização (OLIVEIRA, 2003).

Durante o século XVI o seu quadro natural (composto por vegetação densamente fechada e condições climáticas bastante adversas às européias), aliado aos residentes locais (os índios Tamoios) apresentou-se como forte obstáculo à ocupação da ilha, bem como do restante da região, conhecida atualmente como Costa Verde. O uso desses atributos somente foi superado no final do século XVIII, quando a ilha foi inserida no ciclo econômico da cana de açúcar e do café surgindo, assim, suas primeiras territorialidades materiais como: lavouras, engenhos entre outras construções.

Na última quinzena do século XIX, por intermédio de D. Pedro II, foi construído o Lazareto, inicialmente local de inspeção de embarcações, e mais tarde, em 1903, refuncionalizado como presídio político. Este fixo exerceu sobre a Ilha uma nova centralidade, pelo fato de convergir para a Vila do Abraão diversas atividades transformadoras do espaço local (Santiago, 2009).

Em 1962, este arquétipo é novamente alterado devido à demolição do antigo lazareto no governo Carlos Lacerda, ficando a Ilha voltada às territorializações da Colônia prisional Candido Mendes até 1994, ano de sua desativação. A função prisional da ilha foi responsável pela repulsão de população e turistas, sendo suplantada somente a partir da década de 1970 com a construção da BR 101 e as primeiras políticas públicas no sentido de conservação do meio ambiente (Santiago, op cit e 2010).

Na década de 1990, a desativação do presídio, a instituição dos serviços da empresa Barcas S/A e a queda da atividade pesqueira, devido a problemas ambientais, possibilitaram o crescimento da atividade turística estimulando a proliferação de inúmeros estabelecimentos de hospedagem e alimentação, bem como outros equipamentos e serviços de apoio (Santiago, op cit).

A consolidação da atividade na Ilha Grande redireciona a centralidade da vila de Dois Rios (onde se encontrava a colônia prisional Candido Mendes) para a vila do Abraão, local de maior concentração de equipamentos urbanos e de infra-estrutura de suporte. Sua existência é de extrema relevância à manutenção das condições físicobióticas e sociais, já que por vezes, eles são responsáveis pelas transformações sócioespaciais decorrentes da criação de um novo território para uso do turismo, conforme será detalhado posteriormente.

Geo UERJ - Ano 14, nº 23 , v. 2, $2^{\circ}$ semestre de 2012 p. 389-412

ISSN: 1415-7543 E-ISSN: 1981-9021

http://www.e-publicacoes.uerj.br/index.php/geouerj 
Cabe a esta investigação uma breve reflexão sobre transformações territoriais, visto que o turismo é uma prática socioespacial que gera novos territórios. Essa prática exige o planejamento e a gestão adequados à satisfação do visitante/turista, bem como a manutenção da qualidade ambiental, tendo em vista que o meio ambiente é reflexo das dinâmicas naturais, políticas, econômicas e sociais no espaço geográfico, com destaque, no presente estudo, à Vila de Abraão.

Geo UERJ - Ano 14, no. 23, v. 2, $2^{\circ}$ semestre de 2012 p. 389-412

ISSN: 1415-7543 E-ISSN: 1981-9021

http://www.e-publicacoes.uerj.br/index.php/geouerj 


\section{DISCUTINDO O CONCEITO DE TERRITÓRIO SOB A LÓGICA DO TURISMO NA VILA DO ABRÃ̃O}

Estudar o turismo sob a ótica geográfica demanda a compreensão do seu processo evolutivo nas dimensões social, político, econômico, cultural e ambiental. Isso se explica pela interface natural-humana, característica singular da ciência geográfica. Nesta lógica assume-se, para os fins desta pesquisa, o conceito de território como base teórico-conceitual capaz de apreender a multiplicidade de processos e dimensões do espaço geográfico no que tange ao turismo.

A versatilidade do conceito de território pode ser verificada em ampla literatura. Sob a ótica da multidisciplinaridade o conceito pode ser encontrado, ora nas ciências naturais, ora nas ciências humanas. Seu caráter multiescalar permite aplicação a recortes de indivíduo à território-mundo. Devido a esta capacidade ele assume para a ciência geográfica, extrema relevância no sentido de possibilitar uma pluralidade de abordagens.

Com efeito, os estudos relativos à temática do turismo encontraram no respectivo conceito uma base teórica que norteou a compreensão das transformações que as práticas turísticas impingem no espaço e que por sua vez se traduzem em determinada territorialidade. No que tange ao território, estudos como os desenvolvidos por Raffestin (1980) e Haesbaert (2004), por exemplo, trazem relevantes contribuições ao seu entendimento. Na perspectiva do turismo, trabalhos como de Cruz (2003) e Cooper (et. all. 2001) levantam diversas questões acerca de políticas territoriais, planejamento e gestão da atividade.

A gênese de um território encontra-se no processo de apropriação de uma parcela do espaço geográfico por um determinado grupo social e o reflexo, nele, das relações políticas, sociais, econômicas e culturais manifestadas durante este processo (Haesbaert 2004). Para Harvey (1986, p.193 apud HAESBAERT 1995, p.169) deve ser entendido de forma contextualizada, pois "a apropriação não pode ser compreendida sem o tempo e os ritmos de vida". Com base nessa afirmação foi possível realizar uma caracterização espácio-temporal da Ilha Grande tendo em vista reconhecer a existência de vários territórios e territorialidades pretéritas e presentes em plena convivência, reafirmando a necessidade do planejamento e gestão territorial para promover a

Geo UERJ - Ano 14, nº. 23, v. 2, 2º semestre de 2012 p. 389-412

ISSN: 1415-7543 E-ISSN: 1981-9021

http://www.e-publicacoes.uerj.br/index.php/geouerj 
autonomia de grupos sociais, a manutenção da qualidade ambiental e as funções sociais e culturais que a ilha possui.

Voltados os olhares à Ilha Grande, pode-se afirmar que inúmeros processos de (re)territorialização foram engendrados de acordo com o modo de produção em vigência, expressando assim uma divisão territorial do trabalho nos diferentes momentos de suas história. A apropriação socioespacial ocorrida em função da indústria canavieira e, mais tarde da cafeeira, reflete em primazia a divisão territorial do trabalho exercido na ilha e, por conseqüência, suas múltiplas territorialidades e respectivos conflitos.

De acordo com Raffestin (1993 apud XAVIER, 2008, p.143) “o espaço é a prisão original, o território é a prisão que os homens constroem para si”. Pensando nessa afirmação do autor, um importante marco territorial da Ilha Grande deve ser lembrado: a função efetivamente prisional, a qual fora submetida por mais de um século. Naquela época, a capacidade territorializadora do Estado teve sua expressão máxima, sendo a ilha reconhecida por Santiago (2010), como "Caldeirão do Diabo".

Posteriormente, ocorreu outro processo de (re)territorialização desencadeado pela desativação do Instituto Prisional Cândido Mendes, antiga Colônia Prisional de Dois Rios, que contribui, tanto no sentido de não mais afugentar turistas, mas também oferecendo um importante patrimônio histórico-cultural hoje aberto à visitação, transformado num Eco-museu.

A prática do turismo na natureza permeou a reorganização socioespacial da Ilha Grande a partir da apropriação dos meios de produção, ou seja: dos atributos naturais, da infra-estrutura local, além da mão de obra ociosa com a queda de atividades econômicas pretéritas. Os fixos foram (re)territorializados por agentes internos e externos à lógica do turismo, a despeito das dinâmicas sócio-ambientais pré-existentes. Entre eles cabe ressaltar o objeto de estudo desta pesquisa, os meios de hospedagem que, de acordo com a lei número 11.771 de 17 de setembro de 2008, no seu capítulo V, subseção II, artigo 23 são "os empreendimentos ou estabelecimentos, independentemente de sua forma de constituição, destinados a prestar serviços de alojamento temporário, ofertados em unidades de freqüência individual e de uso exclusivo do hóspede, bem como, outros serviços necessários aos usuários, denominados de serviços de hospedagem, mediante adoção de instrumento contratual,

Geo UERJ - Ano 14, nº. 23, v. 2, 2º semestre de 2012 p. 389-412

ISSN: 1415-7543 E-ISSN: 1981-9021

http://www.e-publicacoes.uerj.br/index.php/geouerj 
tácito ou expresso, e cobrança de diária”. Salienta-se, ainda, na subseção IX, artigo 34 da mesma lei, que encontra-se sob sua responsabilidade: "manter, no exercício de suas atividades, estrita obediência (...) à legislação ambiental”.

Para Cruz (2003, p.18), da apropriação de espaços naturais pelo turismo, decorrem transformações espaciais relacionadas, principalmente, aos fatores acessibilidade e hospedagem. Particularmente no caso da Ilha Grande, pode-se observar, e Mendonça (2010) destaca, a rápida proliferação e convergência de infra-estrutura de hospedagem e acessibilidade na Vila do Abraão, sendo neste local o porto principal de acesso de turistas e visitantes de toda a ilha contribuindo para um potencial crescimento de um centro urbano, muitas vezes caótico e desordenado.

Segundo Cooper (et all 2001, p.350) a hospedagem, ou acomodação, é o maior setor dentro da economia turística, e também o mais presente. Dessa maneira, tornam-se preocupante as diretrizes e práticas estabelecidas pela indústria da hospitalidade, dada sua importância e capacidade de influência nas transformações territoriais. Sob a ótica da sustentabilidade ambiental este agente pode traduzir-se em catalisador de impactos socioambientais decorrentes da atividade, uma vez que é comum encontrar os meios de hospedagem muito próximos aos centros de atratividade turística (Cruz, 2003, p.29).

Por sua vez, o ecoturismo é uma das modalidades de turismo na natureza que auxilia o processo de desenvolvimento do turismo em bases sustentáveis. (Costa e Costa, 2010) ressaltam que o planejamento prévio das atividades calcado no conhecimento da realidade socioambiental, a inclusão social, e a educação ambiental voltada à proteção da natureza figuram entre os principais componentes que contribuirão para a manutenção da qualidade do território turístico.

No contexto da inclusão social e da educação ambiental (aspectos considerados básicos, que diferencia o ecoturismo das demais modalidades de turismo na natureza, conforme destacam a EMBRATUR/IBAMA (1994) e Costa (2010), os meios de hospedagem tem um papel importante no desenvolvimento do ecoturismo na Ilha Grande, já que são detentores de agentes sociais (gerentes, funcionários e donos dos estabelecimentos) capazes de implementar ações educativas direcionadas à conservação do meio ambiente local, conforme será diagnosticado a seguir.

\section{PROCEDIMENTOS METODOLÓGICOS}

Geo UERJ - Ano 14, nº. 23, v. 2, 2º semestre de 2012 p. 389-412

ISSN: 1415-7543 E-ISSN: 1981-9021

http://www.e-publicacoes.uerj.br/index.php/geouerj 
A investigação inicialmente foi pautada no (re)conhecimento da área de estudo através do levantamento de dados secundários tais como: trabalhos monográficos, visitas a sites (da Prefeitura Municipal de Angra dos Reis, do Estado do Rio de Janeiro, Comitê de Defesa de Ilha Grande - CODIG, Instituto Estadual do Meio Ambiente INEA) e análise de papers.

Durante este processo foi obtido, através de um site turístico ${ }^{1}$, um mapa temático contendo a relação de meios de hospedagem na Vila do Abraão que serviu de base para a definição do universo de análise. Ao todo, foi identificado na Enseada e Abraão um total de 87 meios de hospedagem, distribuídos em: 5 campings e 82 hotéis (incluindo pousadas, hostels, flats, resorts, entre outros). Como universo amostral foram aplicados 30 questionários, sendo 25 em hotéis e 5 em campings, correspondendo a pouco mais de $30 \%$ do total.

Após este processo, iniciou-se a elaboração dos questionários semi-estruturados contendo perguntas de cunho ambiental, sócio-econômico e sócio-cultural. As perguntas foram elaboradas a fim de conduzir, juntamente com a visão do pesquisador, a análise das transformações socioespaciais ocorrentes na Vila da Abrão, segundo a implantação/ordenamento das atividades (eco) turísticas pelas três categorias de hospedagem supracitadas. Nas perguntas abertas foi destacada a percepção dos empreendedores (dono e/ou gerente) quanto às perspectivas sobre o planejamento, desenvolvimento e gestão da atividade (eco)turística no recorte espacial trabalhado.

Para a aplicação dos questionários foram efetuados dois trabalhos de campo, de quatro dias cada um, nos períodos de 17 a 20 de setembro e 26 a 29 de novembro de 2010. No momento da aplicação foram observados determinados comportamentos e respostas contraditórias, por parte do entrevistado, sendo estes destacados no final dos questionários.

Paralelamente, parte dos depoimentos apresentados nos questionários foi cotejada pelo entrevistador, com a realidade local possibilitando a avaliação das principais transformações espaciais decorrentes das atividades/intervenções implementadas pelos estabelecimentos hoteleiros.

Geo UERJ - Ano 14, nº 23, v. 2, $2^{\circ}$ semestre de 2012 p. 389-412

ISSN: 1415-7543 E-ISSN: 1981-9021

http://www.e-publicacoes.uerj.br/index.php/geouerj 
Por fim, em gabinete, foi efetuada a tabulação e análise dos dados procurando verificar, principalmente, alguns padrões nas transformações sócio-espaciais induzidas pela indústria da hospitalidade e suas repercussões ambientais na Vila do Abraão.

\section{ESTRUTURAÇÃO DA REDE HOTELEIRA E AS PRINCIPAIS TRANSFORMAÇÕES SOCIOAMBIENTAIS DECORRENTES}

A inserção da Ilha Grande no panorama turístico brasileiro propiciou inúmeras transformações de diferentes dimensões espaciais, como: o incremento de seu trade turístico, as mudanças de ordem estrutural na sua população e o surgimento de agentes territorializadores alheios à dinâmica socioespacial da Ilha, a exemplo da atuação do próprio estado. A vila do Abraão é produto de múltiplos momentos históricos e atores sociais e, portanto, resultados de diversos processos de (re)territorialização, conforme será mostrado a seguir.

No caso do recorte espacial desta pesquisa a implantação de equipamentos e infraestrutura urbanos para atender à demanda turística em franco crescimento fica em evidência quando voltados os olhares à hospitalidade. A proliferação de hotéis, pousadas, hostels, flats, campings, entre outros meios de hospedagem, apresentou um crescimento exponencial após o evento de implosão do presídio (em 1994), como ilustra o gráfico 1, correspondendo a um aumento na oferta de leitos e a criação de novos territórios e territorialidades, conforme foi mostrado anteriormente.

\section{Gráfico 1 - Evolução do crescimento da rede hoteleira na Vila do Abraão, nos últimos 30 anos.}




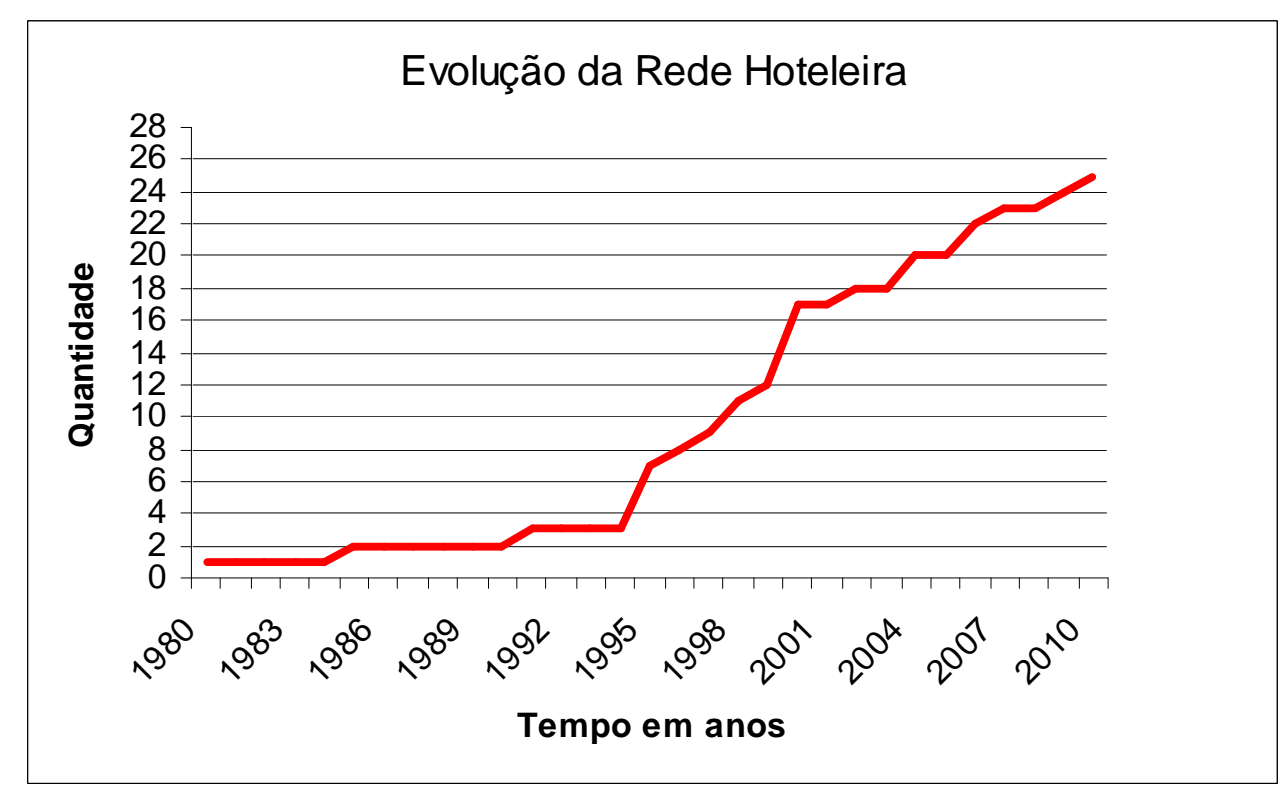

Fonte: elaborada pelos autores com dados coletados em campo (2011).

Salientando as informações do gráfico 1, a implementação da rede hoteleira teve início anos antes da implosão do presídio, embora de maneira incipiente, tomando novas proporções a partir de então. Os dados obtidos em campo permitiram constatar que este processo não se deu de forma planejada, conforme será apresentado posteriormente.

O que foi avaliado é como o receptivo (a rede hoteleira) se estruturou no espaço da Enseada de Abraão e suas principais características no que se refere às suas relações com as práticas (eco)turísticas e as repercussões ambientais.

As análises que se seguem foram pautadas em três perspectivas: ambiental, sociocultural e econômica.

\section{Perspectiva ambiental}

No segmento ambiental foi priorizada a avaliação das relações sociedade-natureza com ênfase nas medidas adotadas pelos empreendimentos hoteleiros a fim de minimizar os impactos negativos no ambiente.

Geo UERJ - Ano 14, nº 23, v. 2, $2^{\circ}$ semestre de 2012 p. 389-412

ISSN: 1415-7543 E-ISSN: 1981-9021

http://www.e-publicacoes.uerj.br/index.php/geouerj 
A educação ambiental, por exemplo, surge como medida capaz de mitigar inúmeras ações perniciosas aos recursos naturais causadas pelos diversos agentes. Neste campo os entrevistados foram inquiridos quanto à existência de programas (e/ou ações) de educação ambiental para turistas e funcionários, sendo encontrado em apenas um estabelecimento, a distribuição de folders e mapas e a divulgação de cartazes com informações relativas ao comportamento adequado a ser mantido pelo visitante/turista durante a estadia na ilha (economia de água e energia, tratamento do lixo e uso consciente dos equipamentos disponibilizados pela administração do empreendimento e pelo poder público).

Sobre a adoção de programas/ações de educação ambiental por parte da rede hoteleira, $44 \%$ dos entrevistados responderam que não tem um programas e/ou ações de educação ambiental pré-estabelecidos; 52\% fornecem algumas informações gerais, oralmente, de como os hóspedes devem proceder dentro da ilha; e ainda, outros $4 \%$, apresentaram efetiva adoção de medidas voltadas à educação ambiental. Durante as observações de campo foi possível constatar atitudes contrárias ao que foi apresentado como proposta educativa por parte dos donos/gerentes de hotéis, a exemplo do descarte de resíduos sólidos diretamente no solo por parte de turistas, além da constatação, em três casos, dos próprios entrevistados serem acometidos da atitude de descarte de seu resíduo por ele produzido (guimba de cigarro) in situ.

Tabela 1 - Adoção de Programas/ações de Educação Ambiental por parte da rede hoteleira.

\begin{tabular}{|c|c|c|c|c|}
\hline \multirow{2}{*}{ Programas ou ações de EA } & \multicolumn{2}{|c|}{ Para Turistas } & \multicolumn{2}{c|}{ Para Funcionários } \\
\cline { 2 - 5 } & Quantitativo & Porcentagem & Quantitativo & Porcentagem \\
\hline Nenhuma Informação & 11 & $44 \%$ & 22 & $88 \%$ \\
\hline Informações Gerais & 13 & $52 \%$ & 2 & $8 \%$ \\
\hline Folders, mapas, cartazes & 1 & $4 \%$ & 1 & $4 \%$ \\
\hline Total & 25 & $100 \%$ & 25 & $100 \%$ \\
\hline
\end{tabular}

Fonte: elaborada pelos autores com dados coletados em campo (2011).

Geo UERJ - Ano 14, nº. 23, v. 2, 2º semestre de 2012 p. 389-412

ISSN: 1415-7543 E-ISSN: 1981-9021

http://www.e-publicacoes.uerj.br/index.php/geouerj 
Outras medidas analisadas em campo foram: a prática da coleta seletiva e a reciclagem de resíduos sólidos. Quanto ao primeiro, verificou-se a existência de iniciativa, por parte dos empreendimentos, da separação de resíduos sólidos em recipientes apropriados. Entretanto, apenas $28 \%$ dos entrevistados optaram por esta intervenção (tabela 2). Em todos os casos, foi apresentado sob forma de protesto, o descaso por parte da Prefeitura em não estimular essa prática. O mesmo foi diagnosticado nos $72 \%$ que não adotaram a medida, alegando que "a prefeitura vem e mistura tudo" (depoimento do representante de um estabelecimento).

No item reciclagem, somente $8 \%$ dos entrevistados apresentaram a iniciativa de venda de latas e garrafas PET, motivados pela possibilidade de retorno financeiro.

Tabela 2: Medidas de Tratamento de Resíduos Sólidos.

\begin{tabular}{|c|c|c|c|c|}
\hline Há medidas de & \multicolumn{2}{|c|}{ Coleta seletiva } & \multicolumn{2}{c|}{ Reciclagem } \\
\cline { 2 - 5 } tratamento? & Quantitativo & Porcentagem & Quantitativo & Porcentagem \\
\hline Sim & 7 & $28 \%$ & 2 & $8 \%$ \\
\hline Não & 18 & $72 \%$ & 23 & $92 \%$ \\
\hline Total & 25 & $100 \%$ & 25 & $100 \%$ \\
\hline
\end{tabular}

Fonte: elaborada pelos autores com dados coletados em campo (2011).

Quanto ao monitoramento ambiental, ou seja, iniciativa de avaliação das condições do entorno da propriedade onde se encontra o estabelecimento, $44 \%$ dos entrevistados apresentaram algum tipo de preocupação com as condições do seu estabelecimento e de seu entorno, verificando periodicamente a existência de lixeiras, condições sanitárias, estrutura predial entre outras adaptações para o desenvolvimento da atividade.

Quando argüidos quanto à utilização de fontes de energia alternativa e renovável, $84 \%$ dos estabelecimentos não apresentaram qualquer tipo de investimento, com apenas $16 \%$ dos hotéis apresentando o uso de energia solar. Nesta questão o que deve ser salientado é a justificativa apresentada pelo grupo que não possui tal tecnologia, sendo argumentado o alto valor monetário do equipamento e a não existência de quaisquer fomentos por parte do setor público para a adesão a esta medida.

O vinculo com guias turísticos e entidades parceiras foi outra dimensão analisada. O guia turístico deve ser um profissional habilitado e gabaritado ao acompanhamento de

Geo UERJ - Ano 14, nº 23, v. 2, $2^{\circ}$ semestre de 2012 p. 389-412

ISSN: 1415-7543 E-ISSN: 1981-9021

http://www.e-publicacoes.uerj.br/index.php/geouerj 
grupos pelos locais turísticos. $\mathrm{Na}$ análise do presente trabalho, entende-se que este profissional deve atuar como um "agente de amortecimento" de conflitos e impactos ambientais decorrentes das atividades exercidas pelos turistas (Alves, 2012, p.587). Neste contexto, verifica-se a necessidade de atuação, por parte dos empreendedores da hospitalidade, no sentido de fornecer e/ou indicar profissionais capacitados e credenciados junto ao Ministério do Turismo, como regulamentado na Lei no 8623/93.

Outra preocupação relativa a esta categoria é a necessidade de priorizar profissionais pertencentes à população local, possibilitando a inserção deste grupo no processo de desenvolvimento da atividade turística, não se estabelecendo assim um turismo segregacional. Nesta perspectiva, 52\% dos entrevistados informaram que já possuem um bouquet de guias credenciados para indicação, em contraposição a $48 \%$ de estabelecimentos sem quaisquer tipos de credenciamento ou indicação. Deste grupo de $52 \%$, apenas três casos assumiram esta preocupação com a inserção da população local na atividade e um caso, em particular, possui estrutura organizacional própria de visitas guiadas (tabela 3 ).

Tabela 3 - Guias Turísticos.

\begin{tabular}{|c|c|c|}
\hline $\begin{array}{c}\text { Possui estrutura } \\
\text { própria? }\end{array}$ & Quantitativo & Porcentagem \\
\hline Sim & 13 & $52 \%$ \\
\hline Não & 12 & $48 \%$ \\
\hline Total & 25 & $100 \%$ \\
\hline
\end{tabular}

Fonte: elaborada pelos autores com dados coletados em campo (2011).

No que diz respeito a entidades parceiras foi verificada a pouca existência de vínculos estabelecidos entre os empreendedores da hospitalidade e os agentes envolvidos direta ou indiretamente no trade turístico. Esse vínculo pode criar um 
ambiente participativo que viabilize soluções adequadas às condições socioambientais existentes na Ilha Grande como um todo.

Tabela 4 - Vínculo com Entidades Parceiras.

\begin{tabular}{|c|c|c|}
\hline $\begin{array}{c}\text { Há vínculo entre empreendedores da } \\
\text { hospitalidade e agentes do trade } \\
\text { turístico? }\end{array}$ & Quantitativo & Porcentagem \\
\hline Sim & 4 & $16 \%$ \\
\hline Não & 21 & $84 \%$ \\
\hline Total & 25 & $100 \%$ \\
\hline
\end{tabular}

Fonte: elaborada pelos autores com dados coletados em campo (2011).

Cabe citar que,nos quatro casos onde ocorre esta iniciativa, as entidades parceiras em questão são: a AMHIG (Associação dos Meios de Hospedagem de Ilha Grande) e o Comitê de Defesa da Ilha Grande (CODIG), não havendo relações de relevância entre os meios de hospedagem e a população local (através da associação de moradores, por exemplo) e órgão públicos.

O último aspecto analisado nesta categoria foi a existência de certificados de sustentabilidade oferecidos por órgãos de avaliação dos meios de hospedagem, empresas de serviços de energia elétrica, entre outras entidades. Neste item apenas um caso apresentou o selo verde oferecido pela Ampla Energia e Serviços S/A, devido ao uso consciente e economia de energia elétrica viabilizados pelo uso da tecnologia de captação de energia solar.

\section{Perspectiva Sociocultural}

A análise relativa à categoria sociocultural teve por objetivo verificar a existência de atividades de valorização histórico-cultural como, por exemplo: apresentações de dança, música, folclore; visitas guiadas; culinária local entre outras. Nesta perspectiva, $76 \%$ dos entrevistados não apresentam quaisquer tipos de atividades, sendo que os $24 \%$ apresentam apenas opções de culinária local (caiçara) e particularmente um caso, além da culinária, apresenta visitas guiadas e filmes relativos ao folclore e documentários dos

Geo UERJ - Ano 14, nº. 23, v. 2, 2º semestre de 2012 p. 389-412

ISSN: 1415-7543 E-ISSN: 1981-9021

http://www.e-publicacoes.uerj.br/index.php/geouerj 
processos de ocupação da ilha e questões culturais (tabela 5). Na realidade, quem exerce tais atividades são moradores locais, muitos deles descendentes dos caiçaras, que são contratados temporariamente para suprir a demanda do período de alta temporada do verão.

Tabela 5 - Valorização Histórico-cultural.

\begin{tabular}{|c|c|c|}
\hline $\begin{array}{c}\text { Há valorização } \\
\text { histórico-cultural? }\end{array}$ & Quantitativo & Porcentagem \\
\hline Sim & 6 & $24 \%$ \\
\hline Não & 19 & $76 \%$ \\
\hline Total & 25 & $100 \%$ \\
\hline
\end{tabular}

Fonte: elaborada pelos autores com dados coletados em campo (2011).

\section{Perspectiva Socioeconomica}

No que tange aos aspectos socioeconômicos foram avaliados questões como: tempo de existência dos meios de hospedagem, capacidade de carga, estrutura de funcionários compra e produção local de alimentos.

A capacidade de carga dos meios de hospedagem, ou seja, o número total de leitos disponíveis para a recepção de turistas é um fator de extrema importância para a gestão e o ordenamento territorial. Este fator deve estar embasado na capacidade de atendimento da infra-estrutura e dos equipamentos urbanos da ilha, já que a relação entre oferta e demanda pode retratar a origem de inúmeros impactos, tais como: congestionamento na rede de distribuição de água e esgoto, colapso da rede elétrica, desgaste e/ou danos às estruturas físicas dos atrativos turísticos, além de impactos diretos ao meio biótico.

Durante a pesquisa foi verificado que o valor absoluto de leitos disponíveis para a recepção de turistas na Vila do Abraão é de 1023 leitos, concentrados principalmente nas pousadas da orla, entretanto, a capacidade máxima de hóspedes que os meios de

Geo UERJ - Ano 14, nº 23, v. 2, $2^{\circ}$ semestre de 2012 p. 389-412

ISSN: 1415-7543 E-ISSN: 1981-9021

http://www.e-publicacoes.uerj.br/index.php/geouerj 
hospedagem entrevistados podem receber é superior a esse valor, principalmente na alta temporada de verão. Este valor refere-se à amostragem de $29 \%$ do universo estudado.

Ao considerarmos que durante os períodos de alta temporada estes meios de hospedagem funcionam com sua capacidade máxima, como informado por todos os entrevistados, e se utilizarmos esta amostragem para inferir o total de hospedes que permanecem na Vila do Abraão durante este período, ou seja, estabelecer a proporção para $100 \%$ dos meios de hospedagem verificar-se-á que sua capacidade máxima é de aproximadamente 3500 hóspedes efetivos na Vila do Abraão.

Acrescentando à população da Vila do Abraão (2072 habitantes) ${ }^{2}$, o máximo de visitantes/turistas constata-se que nos períodos de alta temporada o contingente populacional, somente na Vila do Abraão, ultrapassa os 5.500 pessoas. Isto implica em mais que dobrar a demanda por infra-estrutura e equipamento urbanos em toda a ilha, mesmo existindo outros meios de hospedagem (em menor número) em outras localidades da Ilha.

Este fato pode ser comprovado pelos freqüientes problemas de abastecimento de energia na Ilha Grande, como referenciado por Santiago (2010) e vivenciado pelo autor durante o campo realizado entre os dias 26 e 29 de novembro de 2010.

Além disso, foi verificado por meio das entrevistas, entre outros relatos obtidos em campo, que o quantitativo de resíduos sólidos encontrados disseminados pela vila do Abraão e por algumas trilhas da Ilha Grande (particularmente aquelas que saem de Abraão) aumenta exponencialmente nos períodos de alta temporada, ficando estes "estocados" temporariamente, até a saída da Ilha, no inicio da Estrada da Colônia, próximo ao principal porto da Ilha.

Com relação ao quadro de funcionários procurou-se observar sua origem salientando a necessidade de inclusão social no desenvolvimento do ecoturismo (tabela 6 e gráfico 2) .

Tabela 6 - Origem dos Funcionários.

\begin{tabular}{|c|c|c|}
\hline Origem & Quantitativo & Porcentagem \\
\hline Ilha Grande & 55 & $49 \%$ \\
\hline
\end{tabular}

Geo UERJ - Ano 14, nº 23, v. 2, $2^{\circ}$ semestre de 2012 p. 389-412

ISSN: 1415-7543 E-ISSN: 1981-9021

http://www.e-publicacoes.uerj.br/index.php/geouerj 


\begin{tabular}{|c|c|c|} 
Angra dos Reis & 12 & $11 \%$ \\
\hline Rio de Janeiro & 6 & $5 \%$ \\
\hline Nordeste & 40 & $35 \%$ \\
\hline Total & 113 & $100 \%$ \\
\hline
\end{tabular}

Fonte: elaborada pelos autores com dados coletados em campo (2011).

$\mathrm{Na}$ Tabela acima é possível observar que $49 \%$ dos funcionários vinculados à indústria da hospitalidade (55 funcionários) pertencem à população local, porém, em contraposição, existem outros $51 \%$ externos a esta população. É intrigante neste panorama a relativamente alta margem de nordestinos, (35\%, pertencentes a este grupo) o que leva a inferir sobre a existência de um fluxo migratório nordeste-Ilha Grande, com indivíduos oriundos principalmente dos estados da Bahia e de Pernambuco, como verificado durante a aplicação dos questionários.

A sazonalidade é outro fator de relevância neste aspecto, isto é, a variação do quantitativo de funcionários entre períodos de alta e baixa temporada. No tocante a este fator verificou-se um aumento de $16 \%$ no quadro de funcionários dos meios de hospedagem durante os períodos de alta temporada.

Os últimos aportes analisados nesta categoria foram quanto à origem e produção de alimentos e/ou produtos utilizados por este setor. Não foram encontrados em nenhum dos estabelecimentos analisados quaisquer tipos de produção de alimentos (hortas, pomares) bem como, doces caseiros entre outros. Cabe ressaltar que, $84 \%$ dos estabelecimentos avaliados não utilizam quaisquer alimentos ou produtos encontrados na ilha e ainda, os $16 \%$ que optam por esta iniciativa possuem sérias dificuldades de encontrá-los a preços não inflacionados, servindo-se do continente para obtê-los. (Tabela 7).

Tabela 7 - Origem de produtos e Alimentos.

\begin{tabular}{|l|l|l|}
\hline Origem & Quantitativo & Porcentagem \\
\hline
\end{tabular}

Geo UERJ - Ano 14, nº. 23, v. 2, 2º semestre de 2012 p. 389-412

ISSN: 1415-7543 E-ISSN: 1981-9021

http://www.e-publicacoes.uerj.br/index.php/geouerj 


\begin{tabular}{|c|c|c|} 
Só os poucos encontrados na ilha & 4 & $16 \%$ \\
\hline Continente & 21 & $84 \%$ \\
\hline Total & 25 & $100 \%$ \\
\hline
\end{tabular}

Fonte: elaborada pelos autores com dados coletados em campo (2011).

Apesar de toda a ilha ter vivenciado, no século XVIII, alguns ciclos econômicos voltados à produção agrícola (cana de açúcar e café), estes não se traduzem na sua atual vocação. Hoje, a ilha está voltada às práticas conservacionistas associadas ao uso público das unidades de conservação, com destaque para o desenvolvimento do ecoturismo, no interior do Parque Estadual da Ilha Grande (PEIG). A abundância e a beleza dos recursos naturais, associada ao conhecimento de seu manejo por parte da população local, fazem do turismo ecológico o grande potencial da maior e mais importante ilha do Estado do Rio de Janeiro.

Assim sendo, produzir em pequena escala (nas áreas planas pertencentes à APA Tamoios, unidade de conservação com maior flexibilidade de uso) produtos de subsistência, pode ser uma alternativa viável para suprir as demandas da rede hoteleira, garantindo seu abastecimento com produtos saudáveis e de menor custo, atendendo aos princípios da sustentabilidade.

\section{CONCLUSÕES E CONSIDERAÇÕES FINAIS}

Ao trabalhar sob a ótica da Geografia, a presente investigação constatou que os processos pretéritos de uso do espaço foram de suma importância à compreensão das singularidades territoriais atuais observadas na Ilha Grande.

A partir dos resultados obtidos foi possível concluir que a rede hoteleira não vem contribuindo ao desenvolvimento do ecoturismo em bases sustentáveis. Dentro das estruturas de análise avaliadas nesta pesquisa, o processo de urbanização sofrida pela Vila do Abrão foi pautado na realização do turismo sem a preocupação com a manutenção da qualidade ambiental, com a inserção social e com a mitigação de impactos negativos, apesar de sua elevada potencialidade para tal.

Geo UERJ - Ano 14, nº 23, v. 2, 2º semestre de 2012 p. 389-412

ISSN: 1415-7543 E-ISSN: 1981-9021

http://www.e-publicacoes.uerj.br/index.php/geouerj 
Foi constatado que a indústria da hospitalidade tem seus interesses voltados à apropriação do lugar turístico no sentido de reproduzir suas práticas e ideais particulares, não existindo comprometimento com as lógicas socioespaciais da ilha e com as práticas efetivas de um turismo sustentável. Faltam integração social (entre os meios de hospedagem, população local e poder público) e preocupação quanto ao limites impostos pelas necessidades conservacionistas com relação aos ecossistemas locais. Em outras palavras, as preocupações da rede hoteleira de Abraão estão voltadas para o presente, (visão imediatista de lucro), em detrimento da realização de práticas verdadeiramente ecoturísticas, que visem seu desenvolvimento em bases sustentáveis e conservacionistas.

Prova disso é o rápido, intenso e desregulado processo de turistificação e turismização que a ilha vem sendo submetida, fruto de um turismo de massa. Desta forma, os conflitos territoriais na vila do Abraão são uma constante presença.

Todavia, cabe ao poder público o planejamento e gestão territorial participativos, integrados e estratégicos. Como atividade socioeconômica e ambiental o (eco) turismo deve ser pensado sobre alicerces teórico-conceituais que permitam aos pesquisados, a sociedade civil e ao poder público efetuar a quebra de paradigmas instituídos pelo senso comum. Dizer que o turismo é uma "indústria sem chaminés", ou ainda, que suas lógicas são completamente nocivas ao meio ambiente corresponde a uma perspectiva positivista aliada a interesses escusos e não comprometidos com a reflexão da (e na) sociedade e sua conseqüente ascensão.

\section{NOTAS}

${ }^{1}$ Santiago (2010) reconhece a falta de precisão e a precária atualização dos dados oficiais, desta forma optou-se por trabalhar com os dados disponibilizados pelo site www.ilhagrande.org onde estão registrados os 87 empreendimentos. As análises de campo constataram um universo maior.

${ }^{2}$ Segundo dados da Fundação CIDE (2003) a população residente na Vila do Abrão compõem o valor de 2072 habitantes. (Santiago, 2010).

\section{REFERÊNCIAS BIBLIOGRÁFICAS}

Geo UERJ - Ano 14, nº. 23, v. 2, $2^{\circ}$ semestre de 2012 p. 389-412

ISSN: 1415-7543 E-ISSN: 1981-9021

http://www.e-publicacoes.uerj.br/index.php/geouerj 
ALVES, L. R. dos S.; COSTA, N. M. C. O perfil dos guias de (eco)turismo e de sua atuação no Parque Estadual da Ilha Grande (RJ) In: Revista de ecoturismo, São Paulo, V.5, n.3, set/dez - 2012, p.582-599.

BRASIL. Ministério da Indústria do Comércio e do Turismo. Ministério do Meio Ambiente dos Recursos Hídricos e da Amazônia Legal. Grupo de trabalho interministerial EMBRATUR/IBAMA. Empresários e Consultores Diretrizes para uma Política Nacional de Ecoturismo. Brasília, DF, 1994.

BRASIL. Lei Geral do Turismo $\mathrm{n}^{\circ} 11.711$ de 17 de Setembro de 2008. Brasília: Presidência da República, 2008.

BRASIL. Lei da Profissão dos Guias Turísticos Presidência nº 8.623, de 28 de Janeiro de 1993. Brasília: Presidência da República, 1993.

COOPER, C.; FLETCHER, J.; GILBERT, D.; WANHILL, S. e SHEPHERD, R. (2001), Turismo princípios e prática. 2-ed. - Porto Alegre: Bookman, 2001.

CORREA, R. da S. Diferentes Territórios, Territorialidades Divergentes: os territórios do turismo em Angra dos Reis (RJ) In: MARAFON, G. J. e RIBEIRO M. A. (orgs.). Revistando o Território Fluminense III. Rio de Janeiro: Gramma, 2010, p. 113-134.

COSTA, N. M. C. da. e COSTA, V. C. da. Ecoturism in Brazil: geographical perspectives of development in protected areas. In: Sustainable Tourism IV. Ed. Witpress, Boston - USA. 2010. p. 283-295.

COSTA, R. de O. A. (Re)produção do Lugar Turístico Aliado à Lógica dos Ambientes de Atração Permanente: o exemplo da expansão do fenômeno do ecoturismo na Ilha Grande - Angra dos Reis (RJ) In: MARAFON, G. J. e RIBEIRO M. A. (orgs.). Revistando o Território Fluminense III. Rio de Janeiro: Gramma, 2010, p. 77-87. 
CREED, J. C. Ecossistemas marinhos. In: O Ambiente da Ilha Grande. Orgs: BASTOS, B. e CALLADO,C.H. UERJ/CEADS, R. de Janeiro - RJ, 2009. p. 21-64.

CRUZ, R. de C. A. da. Introdução à Geografia do Turismo. São Paulo: Roca Ed., 2003 $65 \mathrm{p}$.

EMBRATUR/IBAMA. (1994). Diretrizes para uma Política Nacional de Ecoturismo.

Silvio M. Barros II e Denise T. M. de La Penha (coords.): Brasília, Empresa Brasileira de Turismo (EMBRATUR) / Instituto Brasileiro do Meio Ambiente e Recursos Naturais Renováveis (IBAMA) / Ministério da Ciência e Tecnologia (MICT), 1994. Informativo.

GAMA, S. V. G.da, SILVA, L. G. A do E. e SALGADO, M. C. Geologia, relevo e solos. In: O Ambiente da Ilha Grande. Orgs: BASTOS, B. e CALLADO, C. H. UERJ/CEADS, R. de Janeiro - RJ, 2009. p. 21-64.

HAESBAERT, R. O Mito da Desterritorialização: Do "Fim dos Territórios" à Multiterritorialização. Rio de Janeiro: Bertrand Brasil, 2004. 395 p.

HAESBAERT, R. Desterritorialização: entre as redes e os aglomerados de exclusão. In: CASTRO, I. E. de; COSTA, P. C. da e CORREA, R. L. (orgs). Geografia conceitos e Temas. Rio de Janeiro: Bertrand Brasil, 2010, p. 165-205.

MENDONÇA, T.C, de M. Que paraíso é esse? A turismização da Ilha Grande. Tese de doutorado. Programa de Pós-Graduação em Ciências Sociais da Universidade do Estado do Rio deJaneiro. Rio de Janeiro, 2010. 341 p.

OLIVEIRA, M. C. T. O Lugar dos Aventureiros: identidade, dinâmica de ocupação e sistema de trocas no litoral do Rio de Janeiro há 3500 anos antes do presente. Tese de doutorado. Programa de Pós-graduação em História da Faculdade de Filosofias e Ciências Humanas da Pontifícia Universidade Católica do Rio Grande do Sul. Porto Alegre, RS. 2003.

Geo UERJ - Ano 14, nº 23 , v. 2, $2^{\circ}$ semestre de 2012 p. 389-412

ISSN: 1415-7543 E-ISSN: 1981-9021

http://www.e-publicacoes.uerj.br/index.php/geouerj 
RIBEIRO, M. A. Tipologia das atividades turísticas: o exemplo do estado do Rio de Janeiro. IN: Geo UERJ Revista do Departamento de Geografia. UERJ, RJ, n. 13, p.27$38,2003$.

RAFFESTIN, C. Por uma Geografia do Poder. Tradução de Maria Cecília França. São Paulo, Ática, 1993. Título original: Pour une geographie du pouvoir, 1980.

SANTIAGO, A. M. de A.; GUIMARÃES, C.; NOGUEIRA, I.; SANTOS, M. S. dos e SANT'ANNA, T. História da Ilha Grande e patrimônio cultural material e imaterial. In: O Ambiente da Ilha Grande. Orgs: BASTOS, B. e CALLADO,C. H. UERJ/CEADS, R. de Janeiro - RJ, 2009. p. 299-370.

SANTIAGO, A. M. de. De caldeirão do diabo a paraíso ecológico: a conversão da Ilha Grande. Tese (Doutorado em Construção Social do Meio Ambiente) - Universidade do Estado do Rio de Janeiro, Rio de Janeiro - RJ, 2010. 256 p.

XAVIER, T. F. Do território da proteção da natureza: conflitos territoriais no parque Estadual da Ilha Grande, Angra dos Reis. Monografia (especialização em geografia). Instituto de Geociências. Universidade do Estado do rio de Janeiro, 2008, 73 p. 